\title{
The effects of serotonin metabolites on tonic immobility in chickens (Gallus gallus): Dose and time response curves
}

\author{
CHARLES W. HENNIG, CRAIG T. HARSTON, WILLIAM P. DUNLAP, \\ ELIZABETH M. HILL, and MICHAEL D. McNICHOLS \\ Tulane University, New Orleans, Louisiana 70118
}

\begin{abstract}
The effects of melatonin and 5-hydroxyindole acetic acid (5-HIAA) on tonic immobility in chickens were examined at various dosages and after several different postinjection time periods. Both of these metabolic byproducts of serotonin produced increases in duration of immobility at $10 \mathrm{~min}$ postinjection, but melatonin was much more potent than 5-HIAA. In addition, melatonin produced a decrease in the duration of tonic immobility at 120 min postinjection, while 5-HIAA produced a decrease at 60 min postinjection, which was followed by another increase in duration of immobility at $120 \mathrm{~min}$. These results are discussed in terms of possible neurotransmitters and a central feedback system between brain levels of serotonin, its metabolites, and duration of tonic immobility.
\end{abstract}

Tonic immobility (TI), also known as animal hypnosis and death feigning, is a state of motor inhibition in animals that has been recognized for hundreds of years (Maser \& Gallup, 1977). The reaction is usually elicited by inverting an animal and restraining it briefly. At first the animal reacts by struggling and attempting to escape, but after a few seconds it assumes a motionless, catatonic-like posture which persists in the absence of further restraint. This reaction is widespread and has been found in such diverse animal groups as insects, fish, amphibia, reptiles, birds, and mammals (for reviews see Gallup, 1974; Ratner, 1967).

A number of researchers have attempted to treat the immobility response as a model for human hypnotic phenomena (Draper \& Klemm, 1967; Hoskovec \& Svorad, 1969) or compare it to sleep (Chertok, 1968; Svorad, 1957), but experimental evidence seems to suggest that TI actually represents an innate fear reaction. Under natural conditions, tonic immobility is thought to serve as the terminal defense reaction in a sequential series of distance-dependent predator defenses (for reviews, see Gallup, 1977; Ratner, 1967; Sargeant \& Eberhardt, 1975). Recently, it has also been suggested that TI may be related to the type of immobility shown during the retrieval reflex in young mam-

Portions of this paper were presented at the Annual Meeting of the Southwestern Psychological Association in New Orleans, Louisiana in April 1978. Appreciation is expressed to Karl Kelly and Kemper Alston for aid in data collection. Craig T. Harston is now at the Department of Pharmacology, College of Medicine, East Tennessee State University, Johnson City, Tennessee 37601. Requests for reprints should be sent to Charles W. Hennig, now at the Division of Science and Mathematics, Centre College of Kentucky, Danville, Kentucky 40422. mals (Hatton, Reinstein, \& Meyer, Note 1) and the lordosis response in female rats (Naggar \& Komisaruk, 1977). The immobility response has even been proposed as a laboratory model for catatonic schizophrenia (Gallup \& Maser, 1977; Kolpakov, Borodin, \& Barykina, 1977). Therefore, TI is of interest to a wide variety of researchers.

A number of studies have suggested that serotonin plays an active role in the tonic immobility response. One early study demonstrated that injections of ergotamine, a serotonin antagonist, increased TI duration in anoles (Hoagland, 1928), while repeated testing for TI produced a decrease in overall brain serotonin levels in guinea pigs (Liberson, Bernsohn, Wilson, \& Daly, 1964). Wallnau and Gallup (1977) have proposed a serotonergic, midbrain-raphe model of tonic immobility based on findings concerning the effects of monoamine oxidase inhibitors, psychomimetic drugs, serotonin blockers, serotonin, and its precursors on both TI and raphe electrical activity.

\section{EXPERIMENT 1}

Melatonin is the major metabolic product of serotonin produced in the pineal gland (Wurtman, Axelrod, \& Kelly, 1968). Although knowledge of the effects of melatonin is far from complete, it seems certain that this compound has both neural and endocrine effects (for a review, see Minneman \& Wurtman, 1975). Moreover, melatonin injections are thought to increase whole-brain levels of serotonin in rats (Anton-Tay, Chou, Anton, \& Wurtman, 1968), but this effect is complex. Melatonin produced decreases in the serotonin content of the cerebral cortex in rats at 20 and 
60 min postinjection, despite increases in midbrain and hypothalamic serotonin content at longer postinjection times. In addition, melatonin injections decrease the metabolism of serotonergic raphe nuclei in rats (Lloyd, 1974). Therefore, since Wallnau and Gallup (1977) have implicated the control of TI with a serotonergic, midbrain-raphe mechanism, melatonin should have an important role in the immobility response as a modulator of serotonin levels and raphe electrical activity. In addition, Hennig, Dunlap, and Harston (1979) found that injections of melatonin increased the duration of tonic immobility in anoles.

The present study attempts to replicate the latter finding in another species, the domestic chicken, and to determine the dose response characteristics for this drug and tonic immobility. In addition, since melatonin seems to have different effects on serotonin levels in separate brain regions at varied times after injection (Anton-Tay et al., 1968), this experiment also investigates time response characteristics for melatonin and tonic immobility.

\section{Method}

Subjects. The subjects were 100 straight-run Production Red chickens (Gallus gallus), $21 / 2$ to 3 weeks of age, obtained from a local hatchery at 1 day of age and group-reared in thermostatically regulated commercial brooders under a 14-h light cycle (6 a.m. to 8 p.m.). Food (Purina Chick Chow) and water were continually available.

Apparatus and Procedure. In the first part of this experiment, 40 chickens were selected randomly from the brooder on the day of the experiment and divided into four groups of 10 subjects each. One group of 10 chickens received intravenous (i.v.) injections of $.3 \mathrm{cc}$ of $.05 \%$ ethanol (the vehicle). Each of the other three groups received comparable volumes containing $.0065, .065$, or $.65 \mathrm{mg}$ of $\mathrm{N}$-acetyl-5-methoxytryptamine (melatonin) dissolved in $10 \%$ ethanol that was then diluted to a $.05 \%$ concentration of ethanol. All injections were in the humeral wing vein (V. cutanea ulnaris). After testing was completed, the subjects were weighed and an average dose of the drug was calculated for the group. This procedure was used because handling alone can exert a profound effect on tonic immobility (Nash \& Gallup, 1976). The average dosages of melatonin were $.040, .370$, and $4.01 \mathrm{mg} / \mathrm{kg}$ for the respective groups; these amounts are rounded to $.04, .4$, and $4.0 \mathrm{mg} / \mathrm{kg}$ for all further discussions.

Immediately following injection, each subject was placed in a cardboard holding box, carried to the experimental room, and allowed to remain there for a total of $10 \mathrm{~min}$ postinjection. Each bird was then placed on a table and observed for $5 \mathrm{sec}$. If the bird changed position, it was scored as active; if it stood or sat in place, it was scored as passive. Then each subject was picked up and quickly inverted on its right side, whereupon gentle restraint was maintained with both hands for $15 \mathrm{sec}$, after which the experimenter slowly withdrew his hands and activated a stopwatch. While timing the reaction, the experimenter remained relatively motionless, seated about $.5 \mathrm{~m}$ away from the subject and observing it with an indirect gaze. Any subject failing to remain immobile for at least $10 \mathrm{sec}$ was given up to five successive 15-sec inductions in an attempt to elicit immobility, with a 30-sec intertrial interval between attempts. If the subject did not show immobility of at least 10 sec duration for any of the five attempted inductions, a duration score of zero was recorded. For those birds that did become immobile, the duration of TI was measured from the time of release until either the bird showed a spontaneous righting response and returned to its feet or a maximum duration of $3,600 \mathrm{sec}$ had elapsed. Since a number of recent studies (Hennig \& Dunlap, 1977; Rovee, Chiaparelli, \& Kaufman, 1977; Ternes, 1977) have documented circadian rhythms in immobility duration, subjects were tested in random replications so that any possible circadian rhythm effects were evenly distributed across groups. Testing and data recording were performed by experimenters who were unaware of to which group their subjects belonged.

In the second part of this experiment, the other 60 subjects were assigned randomly to six groups of 10 subjects each on the day of the experiment. Three groups received i.v. injections of $.3 \mathrm{cc}$ of $.05 \%$ ethanol, while the other three groups received comparable volumes containing $.018 \mathrm{mg}$ of melatonin. This produced mean melatonin doses calculated to be $.120 \mathrm{mg} / \mathrm{kg}$. Subjects in one control and one melatonin group were tested $10 \mathrm{~min}$ postinjection, as previously described, while a second control and drug group were tested $60 \mathrm{~min}$ postinjection and the last two groups were tested at $120 \mathrm{~min}$. Subjects were housed in glass terraria for these prolonged time periods and were maintained in cardboard boxes only for the $10 \mathrm{~min}$ immediately prior to testing. All other procedures were the same as in the first part of this experiment.

\section{Results}

The dose response curve for melatonin and the duration of tonic immobility in chickens is depicted in Figure 1. As can be seen, even the lowest dose of melatonin approximately doubled the duration of TI shown by control birds, while the larger doses of melatonin produced further substantial increases in TI duration. Dunnett's (1964) test comparing each melatonin group mean with the control mean showed the differences between the control and each experimental group to be significant $[\mathrm{t}(36)=3.11, \mathrm{p}<.05$; $\mathrm{t}(36)=6.44, \mathrm{p}<.01 ; \mathrm{t}(36)=8.22, \mathrm{p}<.01$, respectively]. The number of inductions required to produce immobility for these four groups are shown in the lower part of Table 1. Although melatonin groups required fewer inductions, the differences between groups were not statistically significant. The general activity levels of the chickens before immobility, however, were affected by the presence of melatonin. As can be seen in Table 1, more subjects became passive after receiving injections of melatonin than did

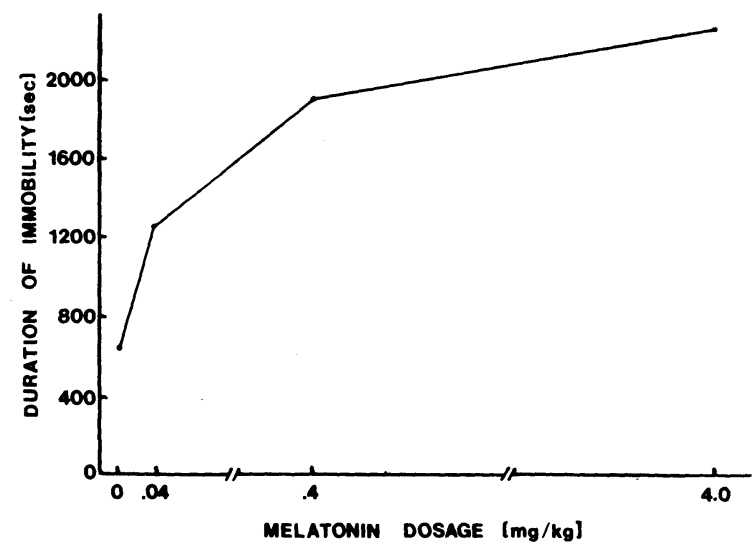

Figure 1. Mean durations of tonic immobility as a function of average melatonin dosage. 
Table 1

Activity State Before Immobility and the Mean Number of Inductions Required to Produce Immobility After Melatonin Injections

\begin{tabular}{|c|c|c|c|c|c|c|c|c|c|c|}
\hline \multirow{4}{*}{$\begin{array}{l}\text { Dependent } \\
\text { Variable }\end{array}$} & \multicolumn{4}{|c|}{ Dose Response Study } & \multicolumn{6}{|c|}{ Time Response Study } \\
\hline & \multirow[b]{3}{*}{ Control } & \multirow{2}{*}{\multicolumn{3}{|c|}{$\begin{array}{l}\text { Groups } \\
\text { Melatonin }(\mathrm{mg} / \mathrm{kg})\end{array}$}} & \multicolumn{6}{|c|}{ Postinjection Time Periods } \\
\hline & & & & & \multicolumn{2}{|c|}{$10 \mathrm{~min}$} & \multicolumn{2}{|c|}{$60 \mathrm{~min}$} & \multicolumn{2}{|c|}{$120 \mathrm{~min}$} \\
\hline & & .04 & .4 & 4.0 & Control & Melatonin & Control & Melatonin & Control & Melatonin \\
\hline Active & 10 & 7 & 5 & 5 & 8 & 2 & 9 & 8 & 8 & 9 \\
\hline Not Active & 0 & 3 & 5 & 5 & 2 & 8 & 1 & 2 & 2 & 1 \\
\hline Inductions & 2.6 & 1.8 & 2.1 & 2.0 & 1.3 & 2.0 & 2.4 & 2.1 & 2.4 & 2.5 \\
\hline
\end{tabular}

subjects after control injections. These differences approached statistical significance $\left[\chi^{2}(3)=7.64\right.$, $\mathrm{p}=.05]$.

In the second part of this experiment, the mean durations of tonic immobility for both melatonin and control groups at 10,60 , and 120 min postinjection are shown in Figure 2. As can be seen, the melatonin group at $10 \mathrm{~min}$ postinjection showed about three times longer mean duration of TI than its control group, while the melatonin group at 120 min produced a decrease in TI duration. A 2-way factorial analysis of variance (ANOVA) with drug treatment and postinjection time as independent variables revealed a

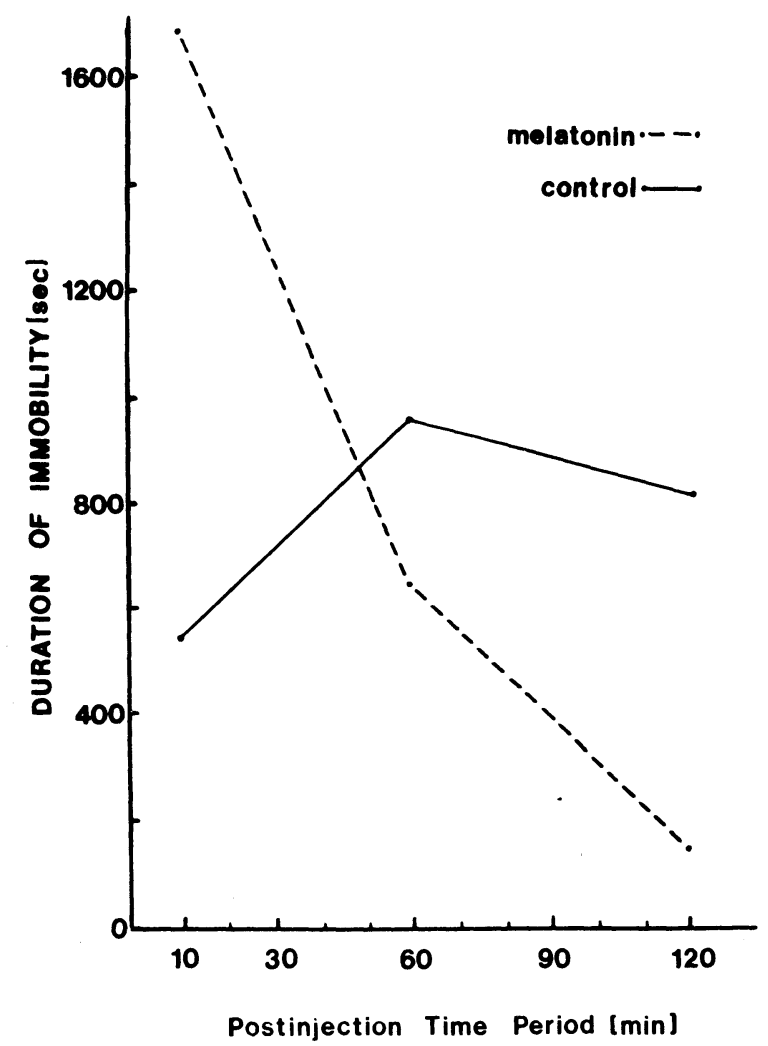

Figure 2. Mean durations of tonic immobility as a function of time after injection $(10,60$, or $120 \mathrm{~min})$ for groups that received either control injections or melatonin (average dose of $.12 \mathrm{mg} / \mathrm{kg}$ ). significant interaction of drug with time $[F(2,54)$ $=4.23, p<.025]$. Analyses of the simple effects revealed that the mean duration of TI for the melatonin group at $10 \mathrm{~min}$ postinjection was significantly greater than the mean for its control $[F(1,54)=$ $5.98, \mathrm{p}<.025]$, while there was no apparent difference between the means for the melatonin and control groups at $60 \mathrm{~min}$ postinjection, and the trend toward a reduced mean duration of TI for the melatonin group at $120 \mathrm{~min}$ postinjection failed to reach statistical significance $[F(1,54)=2.05, p<.20]$. However, the latter result was mostly due to one discrepant response duration. A Fisher's exact probability test showed that of the birds tested with melatonin at 120 min postinjection significantly fewer remained immobile for over $300 \mathrm{sec}$ ( 1 out of 10) than did the controls, where 6 out of 10 birds exceeded the 300 -sec response duration of TI $(p=.027)$. The number of inductions required to produce TI are shown in the lower part of Table 1, but there were no significant effects with this variable. However, melatonin again had an effect on general activity of the chickens prior to the induction of immobility. As can be seen in Table 1, melatonin produced a sedation effect in a large number of subjects at 10 min postinjection, while there was no such effect at longer postinjection times. This was supported by a significant difference in activity only for the chickens in the melatonin group for the shortest postinjection interval $\left[\chi^{2}(1)=7.20, p<.01\right]$.

\section{EXPERIMENT 2}

5-Hydroxyindole acetic acid is the other main metabolic product of serotonin. It is eliminated from the body in the urine after its conversion from serotonin by monoamine oxidase (Cooper, Bloom, \& Roth, 1978). Quay (1964) has measured circadian rhythms of 5-HIAA in rats, and a number of bioassay studies (e.g., Marsden \& Curzon, 1976; Morgan \& Rudeen, 1976; Morgan, Rudeen, \& Pfeil, 1975) have used 5-HIAA as a measure of serotonin turnover, but little else is really known about its function. However, Morgan and Rudeen (1976) found an increase in brain 5-HIAA in rats after prolonged immobilization, while Hennig et al. (1979) have discovered that injections 
of 5-HIAA in anoles increase TI duration, but only at high dosages. The present experiment examines the effect of 5-HIAA on tonic immobility in chickens by quantifying the dose and time response characteristics for this compound.

\section{Method \\ The subjects were 100 straight-run Production Red chickens, $2 \frac{1}{2}$ to 3 weeks of age, obtained and maintained in the same manner as in the first experiment. In the first part of this experiment, 40 chicks were divided into four groups of 10 subjects each. One group received .3-cc injections of saline, while each of the other three groups received comparable volumes containing $.03, .3$, or $3.0 \mathrm{mg}$ of 5-hydroxyindole acetic acid. Then all subjects were tested for TI in the same manner as previously described. The average doses of 5-HIAA were calculated to be $.186,1.87$, and $17.8 \mathrm{mg} / \mathrm{kg}$ for the respective groups; these amounts are rounded to $.2,2.0$, and $20 \mathrm{mg} / \mathrm{kg}$ for further discussion. In the second part of this experi- ment, 60 chicks were divided into six groups of 10 subjects each and were tested for $\mathrm{TI}$ at 10,60 , or $120 \mathrm{~min}$ after receiving $.3 \mathrm{cc}$ injections of saline or a comparable volume containing $3.0 \mathrm{mg}$ of 5-HIAA. This produced an average dose of 5-HIAA calculated to be $21.8 \mathrm{mg} / \mathrm{kg}$. All other procedures were the same as in the latter half of the previous experiment.}

\section{Results}

The dose response curve for 5-HIAA and duration of tonic immobility is shown in Figure 3. Only the highest dose of 5-HIAA produced any substantial increase in duration of immobility. Due to extreme skewness in the data, square root transformations were performed on all scores before statistical analysis. Dunnett's test comparing each 5-HIAA group mean with the control mean failed to show significant differences between these groups, although the comparison of the control with the largest dose group of 5-HIAA did approach significance $[\mathrm{t}(36)=2.27$, $\mathrm{p}<.10$ ]. In addition, a Fisher's exact probability test showed that of the birds tested with $20 \mathrm{mg} / \mathrm{kg}$ of 5-HIAA significantly more remained immobile for over $1,000 \mathrm{sec}$ ( 7 out of 10 ) than did the controls, where 2 out of 10 birds exceeded a 1,000-sec response duration of TI $(p=.032)$. The number of inductions required to produce TI are shown in Table 2, but there were no apparent differences between groups with this measure. The general activity of the chicks before induction of TI also appears in this same table. Although 5-HIAA seems to produce some sedation in

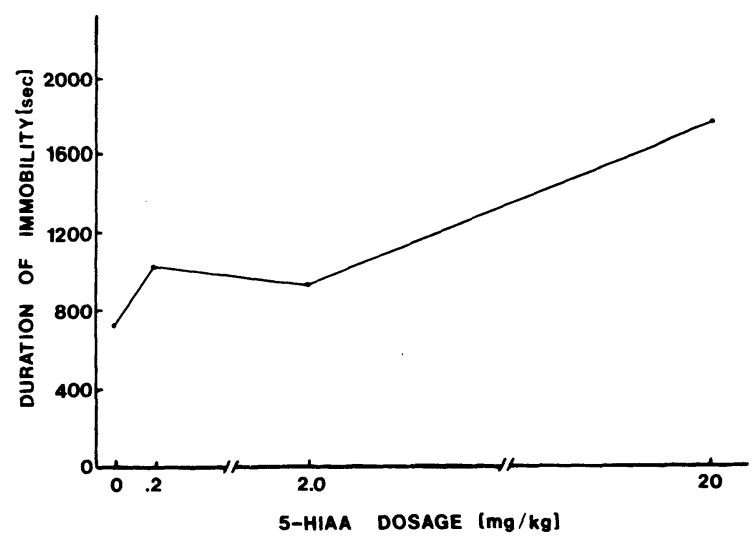

Figure 3. Mean durations of tonic immobility as a function of average 5-HIAA dosage.

chicks, there was no significant difference between groups for this variable.

In the second part of this experiment, the mean durations of tonic immobility for both 5-HIAA and control groups at 10,60 , and 120 min postinjection are shown in Figure 4. The 5-HIAA group at $10 \mathrm{~min}$ postinjection produced approximately a three times longer duration of TI than its control group, while the 5-HIAA group at 60 min produced a decrease in TI, followed by another increase in duration of immobility at $120 \mathrm{~min}$. After a square root transformation, a two-way factorial ANOVA revealed a significant interaction of drug condition and postinjection time period $[\mathrm{F}(2,54)=4.79$, $\mathrm{p}<.025]$. Subsequent analyses of the simple effects revealed that the mean duration of TI for the 5-HIAA groups at 10 and 120 min postinjection was significantly greater than the means for their respective controls $[F(1,54)=5.65, \mathrm{p}<.05 ; \mathrm{F}(1,54)=4.26$, $\mathrm{p}<.05]$, while the mean duration of TI for the 5-HIAA group at $60 \mathrm{~min}$ postinjection showed a trend toward a smaller response duration than its control, but did not reach statistical significance $[F(1,54)=2.44$, $\mathrm{p}<.15$ ]. However, the latter result was mostly due to two discrepant scores. A Fisher's exact probability test showed that of the birds tested with 5-HIAA at $60 \mathrm{~min}$ postinjection significantly fewer remained immobile for over $300 \mathrm{sec}(2$ out of 10$)$ than did the controls, where 8 out of 10 birds exceeded a 300 -sec response

Table 2

Activity State Before Immobility and the Mean Number of Inductions Required to Produce Immobility After 5-HIAA Injections

\begin{tabular}{|c|c|c|c|c|c|c|c|c|c|c|}
\hline \multirow{4}{*}{$\begin{array}{c}\text { Dependent } \\
\text { Variable }\end{array}$} & \multicolumn{4}{|c|}{ Dose Response Study } & \multicolumn{6}{|c|}{ Time Response Study } \\
\hline & \multirow[b]{3}{*}{ Control } & \multirow{2}{*}{\multicolumn{3}{|c|}{$\begin{array}{l}\text { Groups } \\
\text { 5-HIAA (mg/kg) }\end{array}$}} & \multicolumn{6}{|c|}{ Postinjection Time Periods } \\
\hline & & & & & \multicolumn{2}{|c|}{$10 \mathrm{~min}$} & \multicolumn{2}{|c|}{$60 \mathrm{~min}$} & \multicolumn{2}{|c|}{$120 \mathrm{~min}$} \\
\hline & & .2 & 2.0 & 20 & Control & 5-HIAA & Control & 5-HIAA & Control & 5-HIAA \\
\hline Active & 9 & 7 & 7 & 5 & 7 & 4 & 4 & 8 & 4 & 6 \\
\hline Not Active & 1 & 3 & 3 & 5 & 3 & 6 & 6 & 2 & 6 & 4 \\
\hline Inductions & 1.7 & 1.5 & 1.3 & 1.9 & 2.1 & 1.1 & 1.6 & 1.9 & 2.0 & 1.1 \\
\hline
\end{tabular}




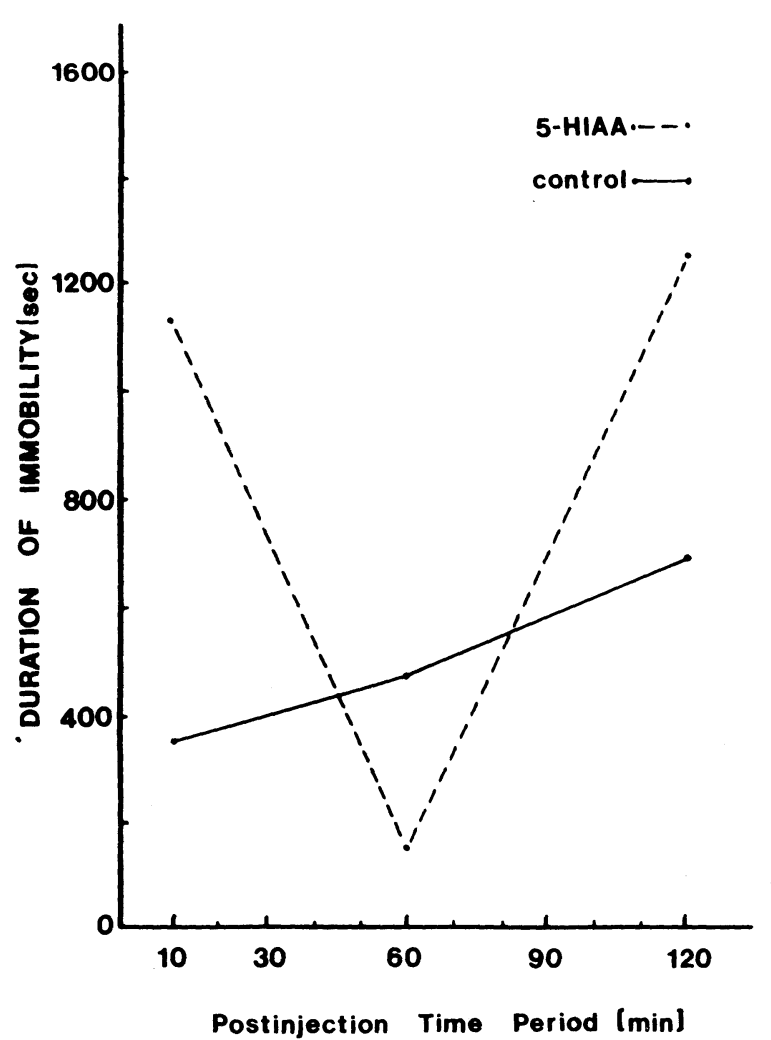

Figure 4. Mean durations of tonic immobility as a function of time after injection $(10,60$, or $120 \mathrm{~min})$ for groups that received either control injections or 5-HIAA (average dose of $21.8 \mathrm{mg} / \mathrm{kg}$ ).

duration of TI $(p=.011)$. The number of inductions required to produce $T I$ and the activity states of the chicks before induction are shown in the lower part of Table 2, but statistical analyses failed to show any differences between groups with these variables.

\section{DISCUSSION}

Melatonin and 5-HIAA both produced significant increases in the duration of TI in the chickens of the present study at $10 \mathrm{~min}$ postinjection. The dose response curves for these drugs also demonstrated that melatonin produced longer durations of TI than 5-HIAA did, and at much lower dosages. This parallels the findings of Hennig et al. (1979) with anoles. However, the meaning of this difference between the potencies of melatonin and 5-HIAA is unclear because of the potential differences in absorption, distribution, metabolism, specificity, and function of these compounds. Nevertheless, the present study suggests the involvement of these 5-HT metabolites with the normal occurrence of the immobility response. In addition, several studies have suggested an inverse relationship between the duration of TI and raphe electrical activity (for a review, see Wallnau \& Gallup, 1977), and Lloyd (1974) found that melatonin can produce a very strong inhibition of raphe metabolism. Therefore, the present findings are consistent with a negative feedback control for TI based on inhibition of raphe nuclei by serotonin metabolites.

The current experiments also provided a picture of the time response characteristics for these drugs and the duration of tonic immobility. Melatonin and 5-HIAA both produced initial increases in the duration of TI, followed by significant decreases in TI duration. This may be due to the common action of these two compounds on the same neural substrate, which may be the 5-HT raphe neurons. Raphe activity, in turn, is related to changes in 5-HT, and Anton-Tay et al. (1968) found that melatonin produced an increase in overall brain levels of serotonin in the rat. However, there were differences in the time of onset for the decreases in TI duration caused by melatonin and 5-HIAA. Melatonin produced a decrease in TI duration at 120 min postinjection, while 5-HIAA caused a decrease in TI at $60 \mathrm{~min}$, followed by another increase in TI duration at 120 min after injections. This may simply be due to the fact that melatonin produces a stronger initial increase in TI duration than 5-HIAA, and may take longer to recover from than the increase produced by the latter drug. However, such a system would not necessarily be as simple as one might imagine.

Hennig (1980) found that small doses of 5-HT produce increases in TI duration, while larger doses caused a decrease in duration of immobility. Lloyd (1974) found a similar biphasic effect by serotonin on raphe metabolism, and Anton-Tay et al. (1968) showed that melatonin increased brain levels of 5-HT in the rat. Therefore, the present results might represent changes in 5-HT levels after injections of melatonin or 5-HIAA, with an increase in serotonin over time, possibly producing circumstances similar to those found with different dosages of serotonin. But this relationship is even more complex than described so far. Although melatonin causes an increase in overall levels of 5-HT in the rat brain, it also inhibits hypothalamic uptake of serotonin (Cardinali, 1975) and affects levels of 5-HT in the various brain areas of the rat in different ways. Injections of melatonin in rats produced a decrease in 5-HT levels in the cerebral cortex at 20 and 60 min postinjection, an increase in hypothalamic 5-HT at $120 \mathrm{~min}$ and longer postinjection times (Anton-Tay et al., 1968). The differential effects by melatonin on TI at 10 and 120 min postinjection in the present study may be produced by a similar mechanism.

Since one metabolite of serotonin seems to have possible control over the serotonergic system, raphe neurons, and TI duration; perhaps another serotonin metabolite, 5-HIAA, has a similar effect. Relatively little is known about 5-HIAA except that it is a byproduct of serotonin metabolism and is eliminated in the urine, however, it has been found that levels of 5-HIAA in the rat brain are increased after prolonged immobilization (Morgan \& Rudeen, 1976). In addition, it was found that immobilization of rats produced early increases in 5-HIAA in the cerebral cortex, but 5-HIAA in the brainstem only increased after much 
longer periods (Morgan et al., 1975). Thus, one can see why there might be differential increases and decreases in TI durations as various areas of the brain are affected by the 5-HIAA levels.

The present study also examined the possible effect by 5-HIAA and melatonin on susceptibility to TI, as measured by the number of inductions required to produce tonic immobility, but found no apparent effect with this variable. This supports the negative findings by Hennig et al. (1979) with these drugs and this variable in the anole. However, serotonin has been found to increase susceptibiltiy to TI in chickens (Hennig, 1980), and 5-HTP, its precursor, is known to increase susceptibility to TI in anoles (Hennig et al., 1979). This apparent difference between the effects of 5-HT and 5-HTP on susceptibility to TI, as compared to the lack of effect by the metabolites of serotonin, suggests that there are two distinct aspects of TI, susceptibility and duration, each with different control systems.

The decreases in the general activity level of the chickens at $10 \mathrm{~min}$ after injections of melatonin or 5-HIAA also seem to suggest the involvement of other types of behavioral inhibition with these same drugs that are correlated with increases in TI duration. Although the extent of the relationship between TI and general activity is unknown, those situations which can be expected to affect freezing or flight (fear reactions) are also known to facilitate the immobility response (Gallup, 1977). Tonic immobility has even sometimes been compared to sleep (Svorad, 1957) and melatonin has produced sleep in chickens, cats, and humans (Cramer, Rudolph, Consbruch, \& Kendel, 1974; Hishikawa, Cramer, \& Kuhlo, 1969; Marczynski, Yamaguchi, Ling, \& Grodzinska, 1964), while the present study and Hennig et al. (1979) have shown that melatonin increases the duration of TI in chickens and anoles.

There is also another possible correlation between TI and behavioral inhibition that may be pertinent to this matter. Gallup and Maser (1977) have suggested TI as an animal model for catatonic schizophrenia in humans. If their hypothesis is valid, then our present findings would suggest that catatonics should have higher levels of melatonin and 5-HIAA than normal persons. Therefore, it is highly intriguing to find that catatonic patients have significantly higher levels of 5-HIAA in their urine than either normal people or other types of schizophrenics (Buscaino \& Stefanachi, 1958).

\section{REFERENCE NOTE}

1. Hatton, D. C., Reinstein, D., \& Meyer, M. E. Methoxamine and retrieved reflex in young rats. Paper presented at the meeting of the Psychonomic Society, San Antonio, November 1978.

\section{REFERENCES}

Anton-Tay, F., Chou, C., Anton, S., \& Wurtman, R. J. Brain serotonin concentration: Elevation following intraperitoneal administration of melatonin. Science, 1968, 162, 277-278.

Buscaino, G. A., \& Stefanachi, L. Urinary excretion of 5-hydroxyindole acetic acid in psychotic and normal subjects. AMA Archives of Neurology and Psychiatry, 1958, 80, 78-85.

Cardinali, D. P. Changes in hypothalamic neurotransmitter uptake following pinealectomy, superior cervical ganglionectomy or melatonin administration to rats. Neuroendocrinology, 1975, 19, 91-95.

Che rtok, L. Animal hypnosis. In M. W. Fox (Ed.), Abnormal behavior in animals. Philadelphia: Saunders, 1968.

Cooper, J. R., Bloom, F. E., \& Roth, R. H. The biochemical basis of neuropharmacology (3rd ed.). New York: Oxford University Press, 1978.

Cramer, H., Rudolph, J., Consbruch, U., \& Kendel, K. On the effects of melatonin on sleep and behavior in man. Advances in Biochemical Psychopharmacology, 1974, 11, 187-191.

Draper, D. C., \& KLемm, W. R. Behavioral responses associated with animal hypnosis. Psychological Record, 1967, 17, 13-21.

DunnetT, C. W. New tables for multiple comparisons with a control. Biometrics, 1964, 20, 482-491.

Gallup, G. G., JR. Animal hypnosis: Factual status of a fictional concept. Psychological Bulletin, 1974, 81, 836-853.

Gallup, G. G., Jr. Tonic immobility: The role of fear and predation. Psychological Record, 1977, 27 (Special Issue), 41-61.

Gallup, G. G., Jr., \& MaSe R, J. D. Tonic immobility: Evolutionary underpinnings of human catalepsy. In J. D. Maser \& M. E. P. Seligman (Eds.), Psychopathology: Experimental models. San Francisco: Freeman, 1977.

HENNIG, C. W. Biphasic effects of serotonin on tonic immobility in domestic fowl. Pharmacology, Biochemistry \& Behavior, 1980,12 , in press.

Hennig, C. W., \& Dunlap, W. P. Circadian rhythms of tonic immobility in the rat: Evidence of an endogenous mechanism. Animal Learning \& Behavior, 1977, 5, 253-258.

Hennig, C. W., Dunlap, W. P., \& Harston, C. T. Tonic immobility and skin color in anoles: Effects of serotonin precursors and metabolites. Physiology \& Behavior, 1979, 22, 1079-1088.

Hishikawa, Y., Cramer, H., \& Kuhlo, W. Natural and melatonininduced sleep in young chickens-A behavioral and electrographic study. Experimental Brain Research, 1969, 7, 84-94.

Hoagland, $\mathrm{H}$. On the mechanism of tonic immobility in vertebrates. Journal of General Physiology, 1928, 11, 715-745.

Hoskovec, J., \& SvoraD, D. The relationship between human and animal hypnosis. American Journal of Clinical Hypnosis, 1969, 11, 180-182.

Kolpakov, V. G., Borodin, P. M., \& Barykina, N. N. Catatonic behaviour in the Norway rat. Behaviour, 1977, 62, 190-207.

Liberson, W. T., Bernsohn, J., Wilson, A., \& Daly, V. Brain serotonin content and behavioral stress. Journal of Neuropsychiatry, 1964, 5, 363-365.

LLOYD, O. L. Inhibition of median raphe neurone metabolism by cerebrospinal fluid (CSF) containing 5-hydroxytryptamine and melatonin. Biochemical Pharmacology, 1974, 23, 1913-1915.

Marczynski, T. J., Yamaguchi, N., Ling, G. M., \& Grodzinska, L. Sleep induced by the administration of melatonin (5-methoxy$\mathrm{N}$-acetyltryptamine) to the hypothalamus in unrestrained cats. Experientia, 1964, 20, 435-436.

Marsden, C. A., \& Curzon, G. Effects of altered brain 5hydroxytryptamine and 5-hydroxyindole acetic acid. Neuropharmacology, 1976, 15, 703-708.

Maser, J. D., \& Gallup, G. G., Jr. Tonic immobility and related phenomena: A partially annotated, tricentennial bibliography, 1636-1976. Psychological Record, 1977, 27 (Special Issue), 177-217. 
Minneman, K. P., \& Wurtman, R. J. Effects of pineal compounds on mammals. Life Sciences, 1975, 17, 1189-1200.

Morgan, W. W., \& Rudeen, P. K. Temporal study of 5-hydroxyindole acetic acid normalization during recovery from immobilization stress. Experimental Neurology, 1976, 51, 259-262.

Morgan, W. W., Rudeen, P. K., \& Pfeil, K. A. Effect of immobilization stress on serotonin content and turnover in regions of the rat brain. Life Sciences, 1975, 17, 143-150.

Naggar, A. N., \& Komisaruk, B. R. Facilitation of tonic immobility by stimulation of the vaginal cervix in the rat. Physiology \& Behavior, 1977, 19, 441-444.

Nash, R. F., \& GalluP, G. G., JR. Habituation and tonic immobility in domestic chickens. Journal of Comparative and Physiological Psychology, 1976, 90, 870-876.

QuAY, W. B. Circadian and estrous rhythms in pineal melatonin and 5-hydroxyindole-3-acetic acid. Proceedings of the Society of Experimental and Biological Medicine, 1964, 115, 710-713.

RATNER, S. C. Comparative aspects of hypnosis. In J. E. Gordon (Ed.), Handbook of clinical and experimental hypnosis. New York: Macmillan, 1967.
Rovee, C. K., Chiaparelli, W. J., \& Kaufman, L. W. Influence of altered lighting regimes on the periodicity of death feigning. Physiology \& Behavior, 1977, 18, 179-182.

Sargeant, A. B., \& Eberhardt, L. E. Death feigning by ducks in response to predation by red foxes (Vulpes fulva). American Midland Naturalist, 1975, 94, 108-119.

Svorad, D. "Animal hypnosis" (Totstell reflex) as experimental model for psychiatry. AMA Archives of Neurology and Psychiatry, 1957, 77, 533-539.

Ternes, J. W. Circadian susceptibility to animal hypnosis. Psychological Record, 1977, 27 (Special Issue), 15-19.

Wallnau, L. B., \& Gallup, G. G., JR. A serotonergic, midbrainraphe model of tonic immobility. Biobehavioral Reviews, 1977, 1, 35-43.

Wurtman, R. J., Axelrod, J., \& Kelly, D. E. The pineal. New York: Academic Press, 1968.

(Received for publication December 14, 1979; revision accepted January 30, 1980.) 